\title{
Necrotizing fasciitis caused by the treatment of chronic non-specific back pain
}

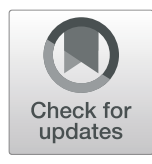

\author{
Lilit Floether $^{1 *}$ (D) Michael Bucher ${ }^{1}$, Ralf Benndorf ${ }^{2}$ and Anna-Maria Burgdorff ${ }^{1}$
}

\begin{abstract}
Background: Chronic back pain is a multifactorial disease that occurs particularly in adults and has many negative effects on the quality of daily life. Therapeutic strategies are often multimodal and designed for a long-term therapy period. In some cases, one option is joint infiltration or intrathecal injection with local anaesthetics. An adverse effect of this intervention may be necrotic fasciitis, a disease with high mortality and few therapeutic options.

Case presentation: This case shows a 53-year-old female patient who developed necrotic fasciitis after infiltrations of the sacroiliac joint and after epidural-sacral and intrathecal injections.

Conclusion: Thanks to early and aggressive surgical intervention, antibiotic treatment and hyperbaric oxygenation, she survived this serious complication and was able to return to life.
\end{abstract}

Keywords: Chronic back pain, Necrotizing fasciitis, Hyperbaric oxygenation, Infiltration

\section{Background}

Chronic back pain is a worldwide disease that affects $70-80 \%$ of all adults during their life. Due to the duration and persistence of pain, it is associated with a significant disability in everyday life as well as a high psychosocial burden. This leads to high health care costs, absenteeism and economic burden $[1,2]$.

Due to the complexity of chronic non-specific back pain, curative therapy usually consists of a multimodal concept. In the national German guidelines for the treatment of non-specific back pain, various non-drug measures (exercise therapy, acupuncture, psychological care) and drug measures (non-opioid analgesics, opioids) are recommended, whereby no recommendation could be given for invasive or intramuscular (subcutaneous) application [3]. Similarly, the European Guidelines for management of chronic nonspecific low back pain do not recommend epidural corticosteroids, intra-articular (facet) steroid injections and some other invasive

\footnotetext{
* Correspondence: lilit.floether@uk-halle.de

'Department of Anesthesiology and Surgical Intensive Care, University Hospital Halle (Saale), Ernst-Grube-Straße 40, 06120 Halle (Saale), Germany

Full list of author information is available at the end of the article
}

treatments [4]. A necrotizing fasciitis may be a possible, albeit very rare, complication of such an invasive procedure. Causes of necrotizing fasciitis are usually bacterial infections (often beta-hemolytic Group A Streptococci or mixed infections) through injuries to the skin, e.g. punctures or perforations. Risk factors are diseases that often lead to microtrauma of the skin or wound infections, such as peripheral arterial disease, diabetes mellitus or obesity. Its course is characterized by a rapid progression and a high mortality rate of about $20 \%$ [5]. The therapeutic strategies of necrotizing fasciitis include early surgical intervention, antibiotic therapy and adjuvant measures such as hyperbaric oxygenation [6]. In this context, $\mathrm{HBO}$, as part of a multimodal strategy consisting of surgery, antibiotics and intensive care, may reduce mortality from 34 to $11.9 \%$ compared to standard care [7].

The following casuistry describes a 53-year-old female patient who developed a fulminant necrotizing fasciitis after infiltration therapy for chronic non-specific back pain. 


\section{Case presentation}

The 53-year-old patient came to our department as an acute transfer via our central emergency room and presented with clinical symptoms of necrotizing fasciitis.

For more than 6 years, the patient has been complaining of recurrent pain in the lumbar spine with radiation into the right lower leg but without a sensorimotor deficit. In the past years she has presented several times as an outpatient and inpatient for pain therapy, where she received facet joint infiltrations and epidural-sacral injections, which provided her with short-term pain relief. Before her transfer to our clinic, the patient had received infiltrations of the sacroiliac joint (ISG) on January 14 and 18 with bupivacaine $0.5 \%$ and dexmethasone $4 \mathrm{mg}$, epidural-sacral on January 15 and 17 with prilocaine $1 \%$, bupivacaine $0.5 \%$ and triamcinolone $40 \mathrm{mg}$ and intrathecal injections on January 21 with bupivacaine $0.5 \%$ and triamcinolone $40 \mathrm{mg}$ as a part of another inpatient multimodal therapy. Previously known from a computer tomography as reason for the pain episode were intervertebral disc protrusion L2-S1 with spondylarthrosis and facet joint arthrosis as well as irritation of the nerve from L5. The maximum score according Numeric Rating Scale (NRS) was given as 8-10 (previous year NRS 7-8), the walking distance was the same at $400-500 \mathrm{~m}$, and there were still no sensorimotor deficits. The patient's home pain medication included celecoxib $2 \times 100 \mathrm{mg}$ p.o. In addition, oxycodone/naloxone $2 \times 20 \mathrm{mg}$ p.o. and metamizole $4 \times 1 \mathrm{~g}$ intravenously were administered in the hospital. Additional known comorbidities were disc protrusions L3-S1 on the left, accompanied by spondyloarthritis of the lumbar spine, arterial hypertension, epilepsy, hypothyroidism and moderate depressive episodes. Therefore, the patient was also treated with torasemide $1 \times 5 \mathrm{mg}$, bisoprolol $1 \times 5 \mathrm{mg}$, levothyroxine $1 \times 125 \mu \mathrm{g}$, candesartan $1 \times 16 \mathrm{mg}$, amlodipine $1 \times 5 \mathrm{mg}$ and valproate $2 \times 300 \mathrm{mg}$.

Shortly thereafter, the patient showed signs of septic shock which began on January 23 with hypotension and increasing infection parameters (interleukin 6: $2610 \mathrm{pg}$ / $\mathrm{ml}$, CRP $358 \mathrm{mg} / \mathrm{l}$, PCT $1,79 \mu \mathrm{g} / \mathrm{l})$. This was interpreted to be associated with the abovementioned injection therapy. The patient had to be transferred to the intensive care unit. There she received a catecholamine therapy (norepinephrine perfusion with up to $0.2 \mu \mathrm{g} / \mathrm{kg} / \mathrm{min}$ ) and calculated antibiosis with meropenem $(3 \times 2 \mathrm{~g})$ and clindamycin $(3 \times 600 \mathrm{mg})$. Since the patient had progressive pain in the back, right flank and right thigh, a computer tomography examination was performed to find the cause. This examination revealed a necrotizing fasciitis suspicious finding consisting of subcutaneous fluid and air extending from the right thigh to the right knee. The patient presented clinically in a reduced general and obese nutritional state (BMI 31) and exhibited a mild circulatory depression. She suffered from massive pain in the entire right leg and back with accompanying redness of the area descending from the back over the right hip to the right knee. Furthermore, edematous soft tissue tension was palpable ranging from the right ankle to the right shoulder.

Due to the rapidly progressing findings and the prevailing circulatory conditions, the immediate emergency surgical indication for an aggressive debridement of the necrotic tissue was made. The patient received an oral explanation and was intubated and ventilated in the operating room. The clinical findings were examined under anaesthesia, followed by wound debridement and vacuum-assisted-closure therapy (VAC). The patient had to remain intubated and ventilated on the intensive care unit of our hospital. An interdisciplinary discussion of the medical staff made the indication for an adjunctive therapy with $\mathrm{HBO}$. She received a paracentesis and we started immediately with $\mathrm{HBO}$. $\mathrm{HBO}$ was carried out according to Boerema TS 300-90 (one fraction) and Marx TS 240-90 (23 fractions). We continued antibiotic therapy extended by ciprofloxacin $(3 \times 400 \mathrm{mg})$, after microbiological detection of Escherichia coli. In the following weeks, further wound revisions and HBO therapy sessions were carried out. To complement the pain therapy, the patient received a hydromorphone PCIA with 0.5 mg boli to cope pain peaks as well as metamizole $1 \mathrm{~g}$ every $6 \mathrm{~h}$ (Patient controlled intravenous analgesia) and was supported by the pain service unit. Five weeks after admission, the patient underwent plastic surgery with a rotating plastic flap on the right lower leg to the right patella and negative microbiological swab smears (Fig. 1). The further course of the patient was without complications.

\section{Discussion and conclusion}

There are few conservative therapy methods with a significantly positive long-term effect for the treatment of chronic non-specific back pain. For therapy-refractory patients, as described in the present case, a multimodal therapy concept is always required. Injection therapy can be used after individual consideration, but has no evidence-based proven long-term effect [8]. Based on two meta-analyses $[9,10]$, the use of intrathecal and lumbosacral intra-articular injections can be proposed for the treatment of chronic spinal pain and chronic low back pain. However, there are only a few studies that have systematically investigated these procedures, which, moreover, must be regarded as studies of rather limited scientific conclusiveness. In these studies, no hazardous complications such as infections were reported. For instance, Kanai et al. (2017) described the therapy of chronic lower back pain using intrathecal bupivacaine injection as safe and effective [9]. 


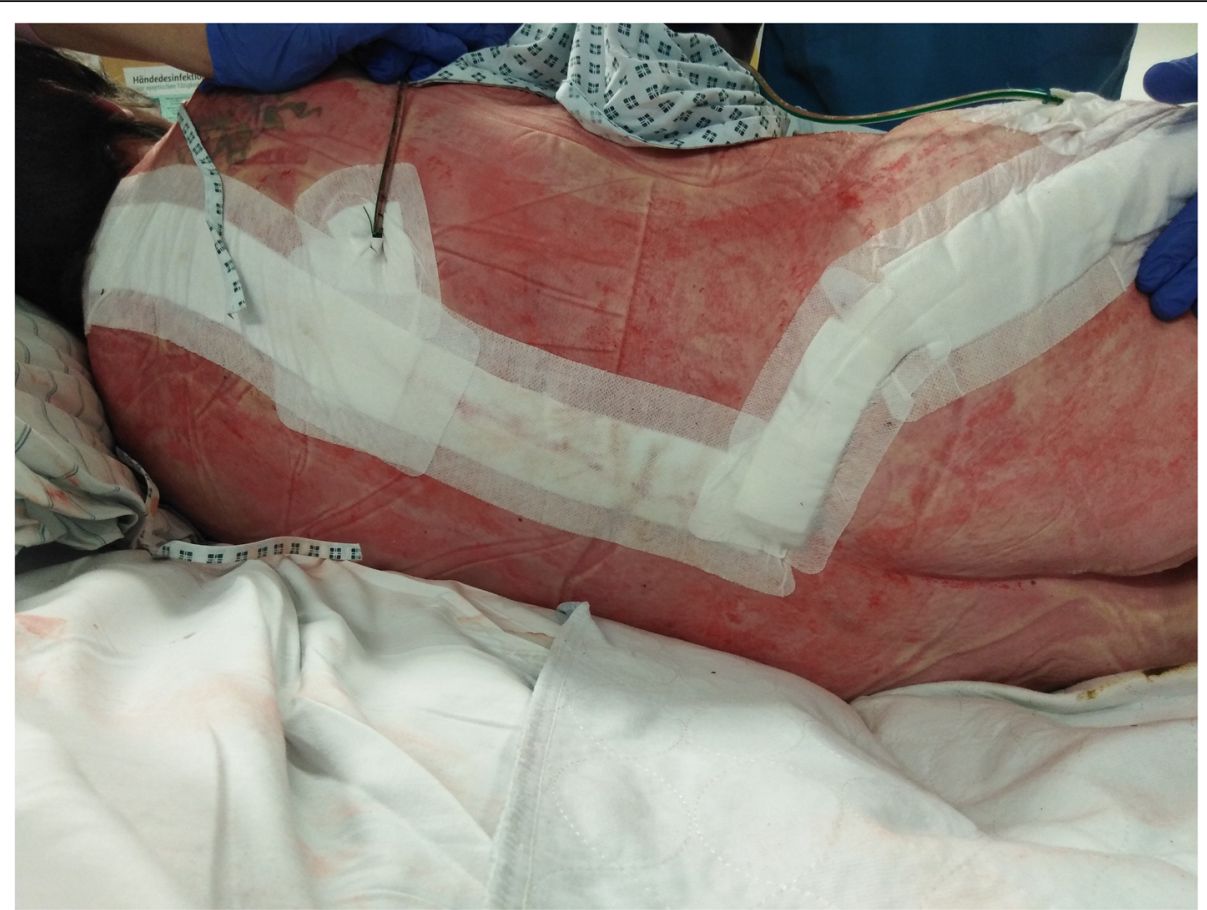

Fig. 1 Results after multiple wound revisions and secondary wound closure

The development of necrotizing fasciitis through injection therapy is nevertheless possible and is accompanied with an extremely complicated course with high lethality $[5,10]$. In addition to the injection, the patient showed other risk factors including arterial hypertension and obesity, as mentioned previously,to develop complications such as necrotizing fasciitis $[5,10,11]$. This emphasizes the importance of the individual risk-benefit assessment that must be carried out before such invasive procedures are used. Nevertheless, the timely diagnosis of necrotizing fasciitis and the transfer to a center with $\mathrm{HBO}$ possibility, as presented in our case, led to a cure of this potential lethal disorder.

The treatment of necrotizing fasciitis consists primarily of early and aggressive surgical treatment as well as accompanying antibiotic therapy and supportive care. It was reported that a treatment delay (mortality from intervention within $24 \mathrm{~h} 6 \%$, between 24 and $48 \mathrm{~h} 24 \%$ ), of the operative care as well as an insufficient surgical debridement contribute to an increase in the mortality rate [6]. There are only few reported experimental data for HBO therapy in necrotizing fasciitis, although clostridial gangrene is considered well studied with this therapy. Nonetheless, a reduction in mortality and morbidity for necrotizing fasciitis with $\mathrm{HBO}$ is suggested based upon results from smaller studies $[6,11]$.

In conclusion the therapy of chronic non-specific back pain continues to be a challenge for doctors and patients. As part of the multimodal pain concept, invasive therapy measures should be discussed and implemented individually. When using injection therapies, these must be carried out strictly aseptically. The development of pain after injections should be accompanied by an immediate consultation with the attending physician in order to be able to identify and treat serious lifethreatening, such as necrotizing fasciitis.

The mainstays of therapy of a necrotizing fasciitis include early and aggressive surgical debridement, antibiotics and supportive care. Adjuvant methods such as protein synthesis inhibitors, hyperbaric oxygen and intravenous immunoglobulin may play a role in the treatment, but further proof of efficacy is necessary to allow for an evidence-based recommendation.

\section{Abbreviations}

BMI: Body-Mass-Index; HBO: Hyperbaric oxygenation; NRS: Numeric Rating Scale; ISG: Sacroiliac joint; VAC: Vacuum-assisted-closure therapy

\section{Acknowledgements}

Not applicable.

\section{Authors' contributions}

LF manage the patient and write the manuscript. MB and RB helped write the manuscript. AMB conduct the background research and helped write the manuscript. All authors read and approved the final manuscript.

\section{Funding}

The University and State Library of the Martin-Luther-University HalleWittenberg supports open access publications with a publication fund to finance the publication fees. The donors had no interest or influence to any parts of this manuscript. They have no knowledge about the content. Open Access funding enabled and organized by Projekt DEAL. 


\section{Availability of data and materials}

The datasets generated and analysed for the case report are not publicly available due to protect participant confidentiality. They are available from the corresponding author on reasonable request.

\section{Ethics approval and consent to participate} Not applicable.

\section{Consent for publication}

Written informed consent to publish the case was obtained from the patient Institutional consent is available.

\section{Competing interests}

The authors declare no competing interests.

\section{Author details}

'Department of Anesthesiology and Surgical Intensive Care, University Hospital Halle (Saale), Ernst-Grube-Straße 40, 06120 Halle (Saale), Germany. ${ }^{2}$ Department of Clinical Pharmacy and Pharmacotherapy, Martin Luther University Halle-Wittenberg, Halle (Saale), Germany.

Received: 3 June 2020 Accepted: 15 September 2020

Published online: 26 September 2020

\section{References}

1. Mathieson S, Kasch R, Maher CG, Pinto RZ, McLachlan AJ, Koes BW, et al, Combination drug therapy for the Management of low Back Pain and Sciatica: systematic review and meta-analysis. J Pain. 2019;20:1-15.

2. Paolucci T, Attanasi C, Cecchini W, Marazzi A, Capobianco SV, Santilli V Chronic low back pain and postural rehabilitation exercise: a literature review. J Pain Res. 2019;12:95-107.

3. Bundesärztekammer, Kassenärztliche Bundesvereinigung, Arbeitsgemeinschaft der Wissenschaftlichen Medizinischen Fachgesellschaften: Nationale VersorgungsLeitlinie Nicht-spezifischer Kreuzschmerz - Langfassung. 2. Auflage. Version 1. Belin; 2017.

4. Airaksinen O, Brox Jl, Cedraschi C, Hildebrandt J, Klaber-Moffett J, Kovacs F, et al. Chapter 4. European guidelines for the management of chronic nonspecific low back pain. Eur Spine J. 2006;15(Suppl 2):S192-300.

5. Friederichs J, Torka S, Militz M, Bühren V, Hungerer S. Necrotizing soft tissue infections after injection therapy: higher mortality and worse outcome compared to other entry mechanisms. J Inf Secur. 2015;71:312-6.

6. Young MH, Engleberg NC, Mulla ZD, Aronoff DM. Therapies for necrotising fasciitis. Expert Opin Biol Ther. 2006;6:155-65.

7. Escobar SJ, Slade JB Jr, Hunt TK, Cianci P. Adjuvant hyperbaric oxygen therapy ( $\mathrm{HBO2}$ ) for treatment of necrotizing fasciitis reduces mortality and amputation rate. Undersea Hyperb Med. 2005;32:437-43.

8. Bredow J, Bloess K, Oppermann J, Boese CK, Löhrer L, Eysel P. Konservative Therapie beim unspezifischen, chronischen Kreuzschmerz: Evidenz der Wirksamkeit - eine systematische Literaturanalyse. Orthopade. 2016;45:573-8.

9. Kanai A, Okamoto T, Hayashi N, Shimao J, Nagahara Y, Fujii K. Short-term results of intrathecal injection of low-dose bupivacaine in outpatients with chronic low back and lower extremity pain. Eur Spine J. 2019;28:250-8.

10. Young MH, Aronoff DM, Engleberg NC. Necrotizing fasciitis: pathogenesis and treatment. Expert Rev Anti-Infect Ther. 2005;3:279-94.

11. Leiblein M, Marzi I, Sander AL, Barker JH, Ebert F, Frank J. Necrotizing fasciitis: treatment concepts and clinical results. Eur J Trauma Emerg Surg. 2018:44:279-90

\section{Publisher's Note}

Springer Nature remains neutral with regard to jurisdictional claims in published maps and institutional affiliations.

Ready to submit your research? Choose BMC and benefit from:

- fast, convenient online submission

- thorough peer review by experienced researchers in your field

- rapid publication on acceptance

- support for research data, including large and complex data types

- gold Open Access which fosters wider collaboration and increased citations

- maximum visibility for your research: over $100 \mathrm{M}$ website views per year

At $\mathrm{BMC}$, research is always in progress.

Learn more biomedcentral.com/submissions 